Journal of Engineering Science and Technology Review 7 (5) (2014) 59-61

Special Issue on Simulation of Manufacturing Technologies
JOURNAL OF

Engineering Science and

Technology Review

Conference Article

\title{
Effect of Process Parameters on Friction Model in Computer Simulation of Linear Friction Welding
}

\author{
A. Yamileva*, A. Chukalova, A. Bikmeyev and R. Gazizov \\ Ufa State Aviation Technical University, Ufa, Russian Federation
}

Received 12 September 2014; Accepted 27 September 2014

\begin{abstract}
The friction model is important part of a numerical model of linear friction welding. Its selection determines the accuracy of the results. Existing models employ the classical law of Amonton-Coulomb where the friction coefficient is either constant or linearly dependent on a single parameter. Determination of the coefficient of friction is a time consuming process that requires a lot of experiments. So the feasibility of determinating the complex dependence should be assessing by analysis of effect of approximating law for friction model on simulation results.
\end{abstract}

Keywords: linear friction welding, friction model

\section{Introduction}

A material model is an indispensable part of accurate modeling of physical processes. Being a part of input parameters set for a computer model, it defines the accuracy of obtained results. As material models are based on experimental data the error in determination its parameters contributes to total model error. Therefore improving the accuracy of measurements will reduce the error of the model. However the material model includes error of the mathematical laws in addition to the experimental error, which is due to the choice of function to approximate experimental data. So it is important to define the mathematical model with an error of the same order as that of the experiments when modelling a physical process.

When numerically modeling linear friction welding (LFW) [1-3] the material model can have a pronounced impact on results as has already been shown [4]. But friction models are an important part of material models which have not been studied extensively to model this process. Existing models employ the classical law of Amonton-Coulomb where the friction coefficient is either constant or linearly dependent on a single parameter, temperature. In this context it is necessary to define the effect of different parameters of friction model have on the LFW modelling results. In this work the feasibility of using more complex, than linear on temperature, dependencies of friction coefficient on the parameters of the welding process are assessed.

\section{Friction model of LFW}

The basic friction model used in most FE software like ANSYS Mechanical is the Amonton-Coulomb law:

\footnotetext{
* E-mail address: a.yamileva@gmail.com

ISSN: 1791-2377 @ 2014 Kavala Institute of Technology. All rights reserved.
}

$\mathrm{F}_{\mathrm{fr}}=\mu \cdot \mathrm{N}$

where $\mathrm{F}_{\mathrm{fr}}$ - friction force, $\mathrm{N}$ - normal pressing force, $\mu-$ friction coefficient, assumed to be function in general case. This law has been used in this paper, and the different dependencies of friction coefficient are studied.

The dependence of friction coefficient on sliding speed has been studied in detail [5] and can be written in form:

$\mu=(a+b v) e^{-c v}+d$,

where $\mathrm{v}$ - sliding speed, $\mathrm{a}, \mathrm{b}, \mathrm{c}, \mathrm{d}$ - parameters which are determined by the nature of rubbing samples and conditions of friction like surface temperature. So, the friction coefficient may be considered as a function of many variables. The complexity of this model lies in the experimental determination of the model parameters. Nevertheless, it is possible to identify the main parameters that affect friction coefficient like temperature, sliding speed, applied pressure, and to assume a simple dependence of friction coefficient on them.

In LFW process the welded samples are oscillating following a sine law:

$x=a \sin (2 \pi \cdot f \cdot t)$

where $\mathrm{x}$ - displacement, $\mathrm{a}$ - amplitude, $\mathrm{f}$ - frequency of periodic motion, $\mathrm{t}$ - time. Applied pressure is constant so it is not necessary to consider a dependency of friction coefficient. So, at the beginning, it is only necessary to consider the dependence on those parameters that change during the process: temperature and sliding speed.

According to available models the dependence of friction coefficient on temperature is significant, so the form of this 
relationship should be investigated. In the case of sliding speed the importance of this parameter will be estimated.

Some variants of friction coefficient functions in LFW have been considered for this. The LFW elastic stage model [6,7] was used, where the elastic stage is sufficient for the qualitative and quantitative assessment in the first approximation, because elastic deformations follows the classical law of dry friction, and the contribution of the friction coefficient in the modelling results is significant. For plastic deformations the adhesion component of friction will be in turn significant. In addition, unlike the elastic formulation, the problem of plastic deformations is not clearly defined (as there are different models of plasticity) and it has a significant contribution to the errors of the material model while reducing the effect of changes in the friction model.

\section{Effect of sliding speed}

There are a few papers on experimental investigations of friction coefficient. In [2, 3] results there are measured for three values of speed: 200,480 and 700 millimeters per second. There appears significant experimental error as data scattering shows. Nevertheless they may be used in qualitative estimation of the speed effect in the friction model.

To add to the complexity of the task there are three variants of the models with different values of process parameters: amplitude, frequency and consequently mean and maximum velocities. These modes are shown in detail in Table 1.

The model is calculated for every mode with the three laws of friction coefficient. In the first, the friction coefficient is dependent upon both temperature and speed, so three experimental curves are used. In the second, the coefficient depends on temperature only based on experimental data for the average speed for current mode. In the third, temperature is also only considered to affect it from experiments performed at speed maximum for current mode. So results from modelling without the friction coefficient dependence on speed (two variants) are compared to those including dependence on speed in the friction model.

Table 1. LFW testing models

\begin{tabular}{|c|c|c|c|}
\hline Parameter & Mode I & Mode II & Mode III \\
\hline Amplitude a, mm & 2 & 2 & 3 \\
\hline Frequency $\mathbf{f}, \mathbf{H z}$ & 30 & 50 & 50 \\
\hline Average speed, $\mathbf{v}_{\text {mean }}, \mathbf{m m} / \mathbf{s}$ & 240 & 400 & 600 \\
\hline Maximum speed, $\mathbf{v}_{\max }, \mathbf{m m} / \mathbf{s}$ & 380 & 628 & 942 \\
\hline $\begin{array}{l}\text { Considered data of friction } \\
\text { coefficient from }[2,3] \text { for } \\
\text { variant } 2 \text { (average speed) }\end{array}$ & $200 \mathrm{~mm} / \mathrm{s}$ & $200 \mathrm{~mm} / \mathrm{s}$ & $480 \mathrm{~mm} / \mathrm{s}$ \\
\hline $\begin{array}{l}\text { Considered data of friction } \\
\text { coefficient from }[2,3] \text { for } \\
\text { variant } 3 \text { (maximum speed) }\end{array}$ & $480 \mathrm{~mm} / \mathrm{s}$ & $480 \mathrm{~mm} / \mathrm{s}$ & $700 \mathrm{~mm} / \mathrm{s}$ \\
\hline
\end{tabular}

The calculated temperature fields along the contact line are plotted in figure 1 for different modes and variants of the friction coefficient. For all modes results for variant 1 (including friction coefficient dependence on speed) are

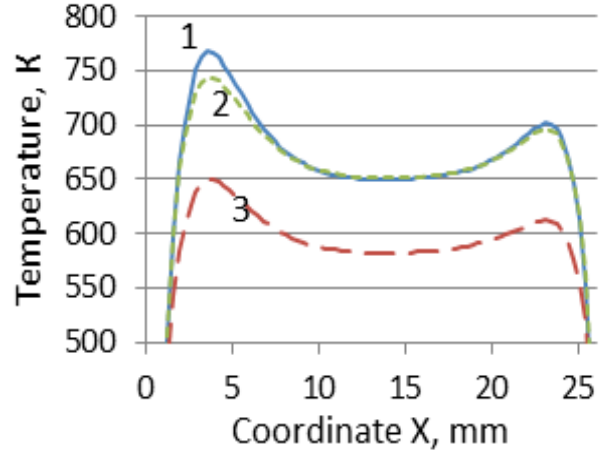

(a)

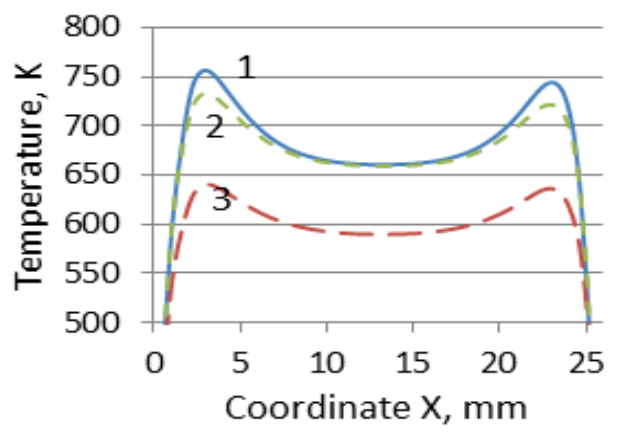

(b)

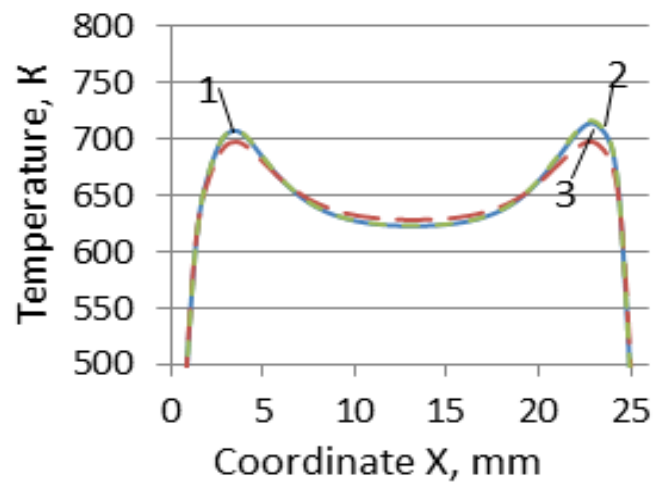

(c)

Fig. 1. Temperature along the contact line in mode I (a), II (b) and III (c) for a friction coefficient dependent on speed (line 1-) and independent of speed for the cases of average (line 2 - -) and maximum (line $3--$ ) speed of process

close to results for variant 3 (without dependence on speed using the data for maximum speed).

So, the dependence of the friction coefficient on temperature, which corresponds to the maximum value of speed, might be used as a first approximation. So friction coefficient can be treated as a function of process mode (instead of sliding speed) and temperature.

\section{Effect of temperature}

The dependence of the friction coefficient on temperature can be approximated from data [3] with polynomials of the 1st, 2nd and 4th order to identify nonlinear effects.

The data available show big variance, possibly due to measurement errors. A confidence band with a confidence level of 0,95 was identified to analyze the effect of these errors on experimental data. A linear approximation was used as mathematical expectation of confidence band. 
Modelling was used for the modes in Table 1. Following the conclusion of previous section, the experimental data for the maximum speed were used in each mode.

Figure 2 shows modelling results for linear and nonlinear laws without significant qualitative and quantitative differences. Results of nonlinear laws are within the limits of the confidence band. Thus nonlinear laws do not significantly increase modelling accuracy and we can use a linear approximation of the experimental data for the dependence of friction coefficient on temperature as the main law.
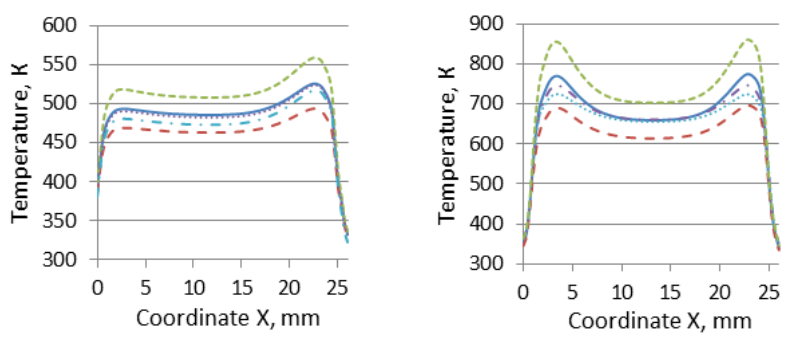

(a)

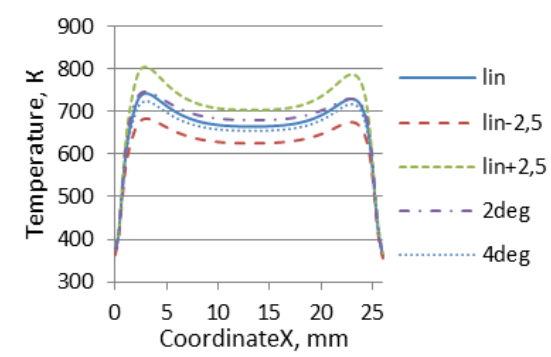

Fig. 2. Temperature along the contact line for mode I (a), II (b) and III (c) for friction coefficient being linearly dependent on temperature (line lin), with second (line 2deg) and forth (line 4deg) power polynomial and for the limits of experimental error range with a linear case (lines lin-2,5, lin+2,5)

\section{Conclusions}

The results of this study show that:

1. The sample speed has small effect on temperature distribution. But it should be pointed out that dependence of the friction coefficient on temperature at the highest speed of process is preferable.

2. The linear approximation for the dependence of friction coefficient on temperature is sufficient for numerical modeling and nonlinear laws do not increase the accuracy of the model significantly.

\section{Acknowledgments}

This work was produced during the joint project between USATU (Ufa State Aviation Technical University) and UMPO (Ufa Engine Industrial Association) with title "Elaboration and industrial development of high-precision shaping coordinated technologies and superficial hardening of responsible details from Al-alloys with heightened constructional energy efficiency", implemented under the contract №40/10-30976 sponsored by the Ministry of Education and Science of the Russian Federation (contract №02.G25.31.0010 between UMPO and the Ministry of Education and Science of the Russian Federation) through the Resolution of the Russian Federation Government № 218 from April 9, 2010.

\section{References}

[1] A.Vairis, N. Christakis. An Analytical Description of the Frictional Behavior of a Titanium Alloy. Research Letters in Materials Science, Volume 2007, Article ID 92170, 2007

[2] Vairis A. Investigation of frictional behavior of various materials under sliding conditions // Eur. J. Mech., A/Solids - 1997 -vol. 16, N. 6. Pp. 929-945.

[3] A.Vairis, M. Frost. On the extrusion stage of linear friction welding of Ti6Al4V. Material Science and Engineering. A 271, (1999), pp 477-484.

[4] R. Turner, F. Schroeder, R. M. Ward, and J. W. Brooks, "The Importance of Materials Data and Modelling Parameters in an FE Simulation of Linear Friction Welding," Advances in Materials Science and Engineering, vol. 2014, Article ID 521937, 8 pages, 2014. doi: $10.1155 / 2014 / 521937$

[5] Vairis, A., "Superplasticity Effects and Strain Rate Dependency in a Material Joining Process", Journal of Engineering Science and Technology Review, 2008, vol.1, pp.28-32.

[6] Bharat Bhushan. Modern tribology handbook. Two volume set CRC Press, 2000. 1762 p.

[7] A.T. Bikmeyev, R.K. Gazizov, A. Vairis, A.M. Yamileva Modelling the temperature distribution in the contact area of a moving object in case of linear friction welding // ASME 2013 International Mechanical Engineering Congress and Exposition Volume 8A: Heat Transfer and Thermal Engineering. San Diego, California, USA, November 15-21, 2013. - 8 p. ISBN: 978-0-7918-5634-5 [doi:10.1115/IMECE2013-64343]

[8] A. Yamileva, R. Gazizov Influence of clamping in computer simulation of the linear friction welding process of aluminum and titanium alloys // Woodhead Publishing Limited, 2013. Proceedings of the International Joint Symposium on Joining and Welding IJSJW 2013, 6-8 November, 2013, Osaka, Japan. pp.339-343. 